\title{
Acinetobacter baumannii producing OXA-23 detected in the Czech Republic
}

\author{
Marketa Senkyrikova ${ }^{1 *}$, Vendula Husickova ${ }^{1}$, Magdalena Chroma², Pavel Sauer ${ }^{1}$, Jan Bardon$^{3}$ and Milan Kolar ${ }^{1}$
}

\begin{abstract}
Background: Acinetobacter baumannii is an opportunistic pathogen posing an increased risk to hospitalized persons, causing nosocomial pneumonias, urinary tract infections and postoperative infections.

Methods: Between 1 December 2011 and 30 September 2012, strains of Acinetobacter spp. were isolated from clinical samples obtained from hospitalized patients. Susceptibility to antibiotics was determined by the standard microdilution method and phenotypic testing was used to detect the presence of serine carbapenemases and metallo-beta-lactamases. The polymerase chain reaction was used to detect the genes encoding carbapenemases. Pulsed field gel electrophoresis was used to investigate the genetic relationship among the carbapenem resistant isolates of Acinetobacter baumannii.
\end{abstract}

Results: In three strains of Acinetobacter baumannii enzyme OXA-23 was detected. This positive result was confirmed by restriction analysis and sequencing. The study reported an OXA-23-producing strains of Acinetobacter baumannii in the Czech Republic. All three strains isolated from Military Hospital patients had a completely identical restriction profile, indicating clonal spread of a strain carrying serine carbapenemase OXA-23 in this health care facility. Moreover this was the first time the strain was detected in the country in patients who had not stayed abroad.

\section{Background}

At present, one of the most serious issues in medicine is increasing resistance of bacterial pathogens to antimicrobial agents. This fact is associated with higher mortality and morbidity rates, prolonged hospital stays and increased treatment-related costs (Rello et al., 1994; Scaife et al., 1995; Luna et al., 1997; Micek et al., 2005; Uvizl et al., 2011; Trecarichi et al. 2011). Such negative trends have also been observed in Acinetobacter spp. strains. Together with isolates of Pseudomonas aeruginosa, Stenotrophomonas maltophilia and Burkholderia cepacia complex, these belong to the clinically most important aerobic non-fermenting Gram-negative rods. The species Acinetobacter baumannii is an opportunistic pathogen with increasing clinical significance, particularly in immunocompromised patients, causing nosocomial infections of the lungs, urinary tract and surgical wounds (Lee et al., 2009).

\footnotetext{
* Correspondence: marketa.senkyrikova@klikni.cz

'Department of Microbiology, Faculty of Medicine and Dentistry, Palacky University Olomouc, Hněvotínská 5, Olomouc 77900, Czech Republic Full list of author information is available at the end of the article
}

Moreover, the role of Acinetobacter baumannii is strengthened by relatively high resistance to numerous antibiotics which is determined by both natural and acquired mechanisms (Jeon et al., 2005). In multiresistant strains of Acinetobacter baumannii, the drugs of choice are carbapenems. Unfortunately, the development of resistance did not spare even this group of antimicrobial drugs, with the main mechanism being production of carbapenemases, enzymes belonging to Ambler classes B, A and D (Ambler, 1980; Bush et al., 2010). From class B carbapenemases known as metallo-beta-lactamases (MBLs), were in Acinetobacter spp. strains detected type of IMP, VIM and SIM enzymes (Zarrilli et al., 2009). However, resistance of Acinetobacter baumannii to carbapenems is more frequently caused by production of class D serine carbapenemases. These enzymes are called carbapenem-hydrolyzing class D beta-lactamases (CHDLs) (Higgins et al., 2010). The first reported acquired class D beta-lactamases with carbapenemase in Acinetobacter baumannii originated from Scotland and is known as OXA-23 (initially refered as ARI-1) (Scaife et al., 1995; Mugnier et al., 2010). The most common 
CHDL subgroups in Acinetobacter baumannii are OXA-23, OXA-24/40 OXA-58, OXA-143 and OXA-51 (Dijkshorn et al., 2007; Higgins et al., 2009). The gene for OXA-51 is located on a chromosome and, unlike the other OXA types able to hydrolyze carbapenems, it has a very low level of expression and does not cause resistance (Dijkshorn et al., 2007).

Nowadays CHDLs are spread worldwide and they are often involved in nosocominal infection (Peleg et al., 2008). Isolates carrying CHDLs were detected in North and South America (Peleg et al., 2008; Villegas et al, 2007; Merkier et al., 2008; Dalla-Costa et al., 2003; Lolans et al., 2006), Africa (Marais et al., 2004), Australia (Peleg et al., 2006), Asian area like China (Zong et al., 2008; Hsueh et al., 2002) Korea (Kim et al., 2008), Thailand (Mendes et al., 2009), Indonesia (Mendes et al., 2009) and also in European countries like the United Kigdom (Coelho et al.; 2006), the Netherlands (van den Broek et al., 2006), France (Corvec et al., 2007), Belgium (Wybo et al., 2007), Burglaria (Stoeva et al., 2008), Belgium (Bogaerts et al., 2006), Greece (Tsakris et al., 2008) or Spain (Acosta et al., 2011).

It must be stressed that resistance of Acinetobacter spp. to carbapenems may be caused by other mechanisms such as changes in porin expression, modification of PBPs or efflux of an antibiotic from a cell (Poirel et al., 2010).

Carbapenem resistance in Acinetobacter baumannii associated with OXA-type enzymes was first occurred in 2008 in the Czech republic. There were detected OXA58-like and OXA-24-like enzymes from patients hospitalized at intensive care units (Nemec et al., 2008). Then a few years later in 2011 was in the Czech republic detected a multiresistant strain of Acinetobacter baumannii carrying the genes for NDM-1 and OXA-23 was detected in 2011 (Kř́žová et al., 2012). However, this strain was isolated in a patient who had returned from a stay in Egypt and belonged to the European (EU) clone I (Křížová et al., 2012).

This is the first report in the Czech Republic of Acinetobacter baumannii strains producing OXA-23 isolated from a patient who did not stay abroad.

\section{Material and methods}

\section{Strain selection}

Between 1 December 2011 and 30 September 2012, Acinetobacter spp. strains were isolated from clinical samples (endotracheal secretion, bronchoalveolar lavage, sputum, blood, urine, pus, aspirate, wound secretion, blood culture). These strains were obtained from patients hospitalized at intensive care units in the University Hospital Olomouc and Military Hospital Olomouc. The identification was performed by standard microbiology procedures including the use of the
Phoenix automated system (Becton, Dickinson and Company) and MALDI-TOF Biotyper (Bruker Daltonics).

\section{Determining resistance to antimicrobial agents}

In all Acinetobacter spp. isolates, susceptibility to antibiotics was determined by a standard microdilution method according to the EUCAST (European Committee on Antimicrobial Susceptibility Testing) criteria (European Committee on Antimicrobial Susceptibility Testing, 2012). The reference strains for quality controls were Escherichia coli ATCC 25922, Escherichia coli ATCC 35218 and Pseudomonas aeruginosa ATCC 27853. Resistance to meropenem determined by the microdilution method was confirmed by the E-test (bioMérieux, France). In case of imipenem and ertapenem, the E-test was also used to determine the minimum inhibitory concentrations (MIC).

\section{Phenotypic determination of carbapenemase production}

Carbapenemase production in Acinetobacter spp. isolates with a MIC for meropenem of $>2 \mathrm{mg} / \mathrm{L}$ was phenotypically determined by the $\mathrm{CD}$ test (Figure 1) for detection of carbapenemases class A, combined disc (Figure 2) and modified Hodge test for serine carbapenemases and MBL detection (Lee et al., 2009; Pasteran et al., 2009; Pournaras et al., 2010).

\section{Genotypic determination of carbapenemase production}

In Acinetobacter baumannii strains with a MIC for meropenem of $>2 \mathrm{mg} / \mathrm{L}$, positively phenotypically tested for carbapenemase, the relevant genes were determined. This was carried out by PCR using specific oligonucleotide primers encoding serine carbapenemases of class A (NMC, SME, IMI, KPC and GES types) and two selected

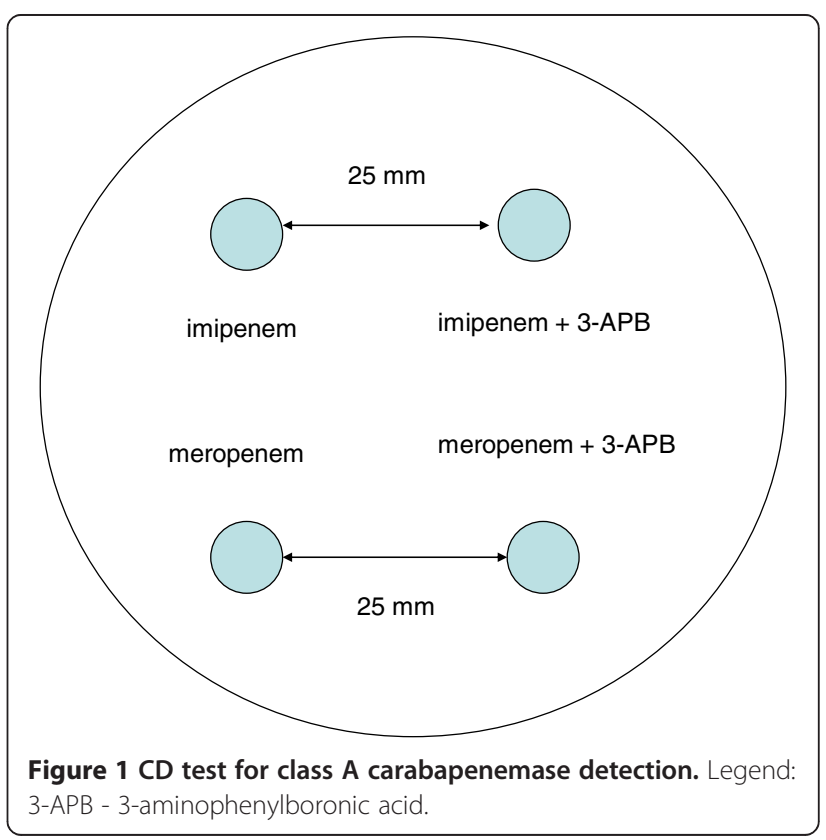




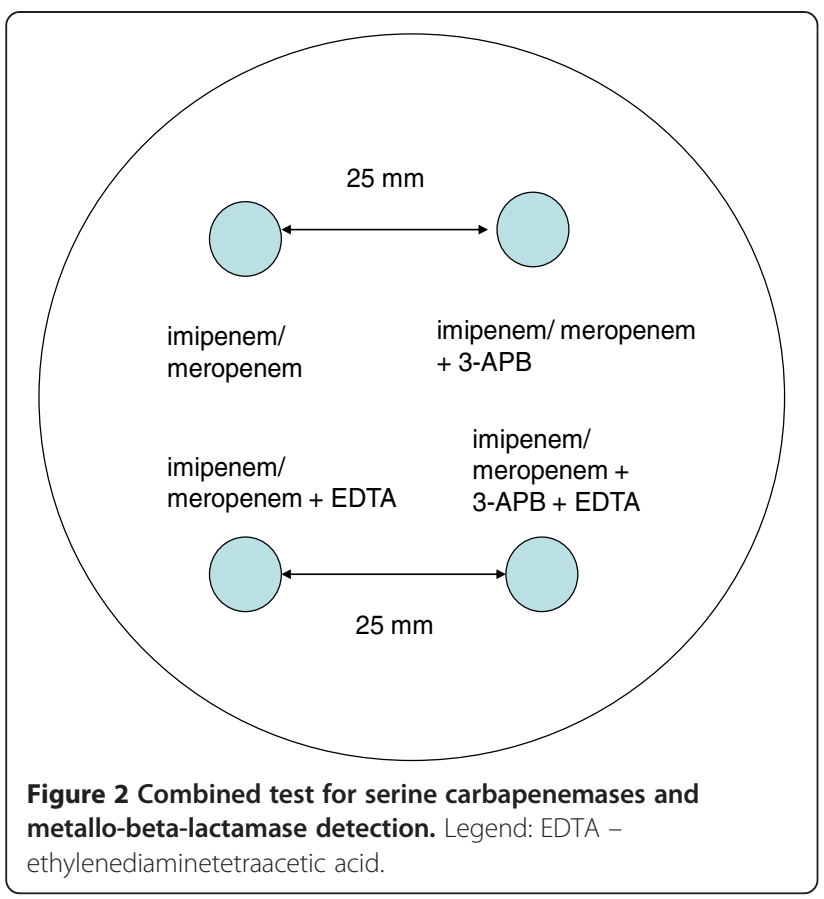

class D types (OXA-23 and OXA-48). Sequences of primers for amplification are shown in Table 1. The positive control was a strain with a known content of carbapenemases (producing KPC-2 enzyme) provided by Ing. J. Hrabák, Ph.D. from the Department of Microbiology, Faculty of Medicine in Pilsen, Charles University in Prague.

Strains selected for gene detection were inoculated onto Mueller Hinton agar (Trios, Czech Republic) and aerobically cultured at $37^{\circ} \mathrm{C}$ for 18 hours. $1-2$ colonies from this fresh culture were resuspended in $100 \mu \mathrm{L}$ of sterile water and heated at $95^{\circ} \mathrm{C}$ for 10 minutes. This was followed by centrifugation at $13,000 \times g$ for 2 minutes. The obtained supernatant served as a template for subsequent PCR using the Robocycler Gradient 96 Temperature Cycler with specific primers shown in Table 1.

The obtained amplicons were subsequently separated on $1.5 \%$ agarose gel and compared with a DNA molecular weight marker (Top-Bio, Czech Republic). Then, OXA-23-positive PCR products were cleaved with the $H p h I$ restriction endonuclease (New England Biolabs, Great Britain) and separated on 1.5\% agarose gel, with cleaved fragment sizes being compared with the molecular weight marker. The amplified gene sequence was confirmed by direct sequencing of a PCR amplicon provided by Elisabeth Pharmacon (Czech Republic) and by comparing the obtained DNA sequence in BLAST (Basic Local Alignment Searching Tool, National Center for Biotechnology Information, www.ncbi.nlm.nih.gov).

\section{Determination of epidemiological relationship}

To determine epidemiological relationship of strains with positive genotypic assay results, macrorestriction profiles of genome DNA were compared by pulsed-field gel electrophoresis (PFGE).

The PFGE analysis was carried out with bacterial DNA isolated from culture freshly grown on Mueller Hinton broth as described previously (Husičková et al., 2012). Bacterial DNA was then cleaved with the SmaI restriction endonuclease (Takara, Japan). The restriction fragments were separated in $1.2 \%$ agarose gel using the

Table 1 Primers for detecting carbapenemases of class A and two selected class D subgroups

\begin{tabular}{|c|c|c|c|c|}
\hline Primer & $\begin{array}{c}\text { Sequence } \\
\left(5^{\prime} \rightarrow 3^{\prime}\right)\end{array}$ & $\begin{array}{l}\text { Product } \\
\text { size (bp) }\end{array}$ & $\mathrm{T}_{\mathrm{a}}$ & Reference \\
\hline SME-F & AGATAGTAAATITTATAG & 1138 & $50^{\circ} \mathrm{C}$ & Radice et al.; 2004 \\
\hline SME-R & CTCTAACGCTAATAG & & & \\
\hline IMI-F & ATAGCCATCCTTGTTTAGCTC & 818 & $50^{\circ} \mathrm{C}$ & Queenan et al.; 2000 \\
\hline IMI-R & TCTGCGATTACTITATCCTC & & & \\
\hline NMC1 & GCATTGATATACCTITAGCAGAGA & 2158 & $50^{\circ} \mathrm{C}$ & Aubron et al.; 2005 \\
\hline NMC4 & CGGTGATAAAATCACACTGAGCATA & & & \\
\hline$K P C-F$ & ATGTCACTGTATCGCCGTCT & 893 & $60^{\circ} \mathrm{C}$ & Bradford et al.; 2004 \\
\hline KPC-R & TITCAGAGCCTTACTGCCC & & & \\
\hline GES-F & GTTTGCAATGTGCTCAACG & 371 & $50^{\circ} \mathrm{C}$ & Weldhagen et al.; 2004 \\
\hline GES-R & TGCCATAGCAATAGGCGTAG & & & \\
\hline OXA-23 F & AAGCATGATGAGCGCAAAG & 1066 & $50^{\circ} \mathrm{C}$ & Donald et al.; 2000 \\
\hline OXA-23R & AAAAGGCCCATTTATCTCAAA & & & \\
\hline OXA-48 F & TTGGTGGCATCGATTATCGG & 744 & $50^{\circ} \mathrm{C}$ & Poirel et al., 2004 \\
\hline OXA-48R & GAGCACTTCTIITGTGATGGC & & & \\
\hline
\end{tabular}

Legend: $T_{a}$ - annealing temperature. 


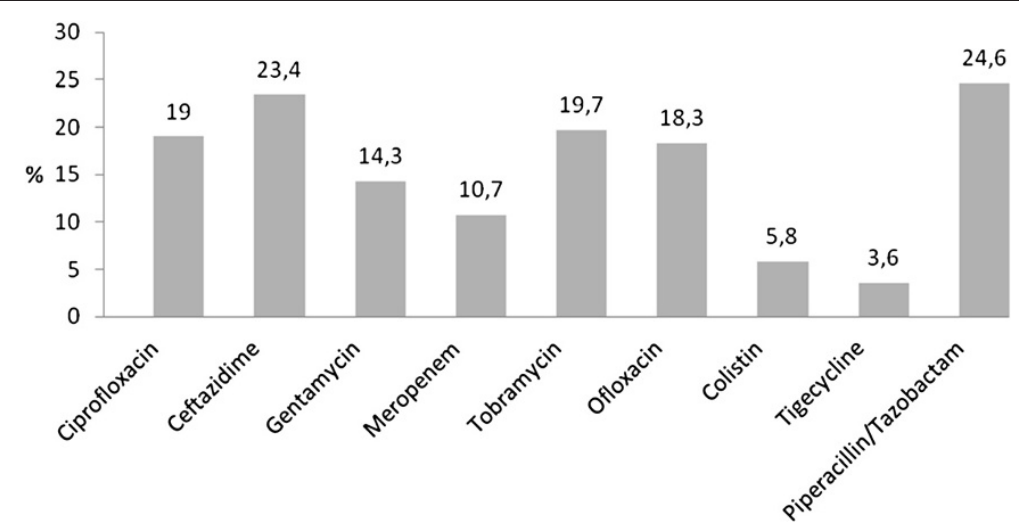

Figure 3 Resistance of Acinetobacter spp. to selected antimicrobial agents (percentages).

CHEF-DRII (Bio-Rad, USA) under the following conditions: $5 \mathrm{~V} / \mathrm{cm}$, switch interval 2-20 seconds, for 20 hours at $14^{\circ} \mathrm{C}$ in $0.5 \times \mathrm{TBE}$ buffer. The gel was stained with ethidium bromide at $0.75 \mu \mathrm{g} / \mathrm{ml}$ for $1 \mathrm{~h}$ and visualized by UV transllumination. A 50-1,000 kb Pulse marker (Sigma, USA) was used to determine the size of DNA fragments. The PFGE results were analysed with GelCompar II (Applied Maths) software.

\section{Results}

Over the study period, a total of 166 Acinetobacter spp. strains were isolated in the two participating hospitals. Figure 3 shows the resistance to antimicrobial agents in a group of 140 isolates assumed to play a role in the etiology of the particular infection. The results revealed a prevalence of meropenem-resistant strains of $10.7 \%$.

From the group of 140 strains, a total of 15 strains were found to be resistant to meropenem using the standard microdilution method. The phenotypic assay demonstrating production of carbapenemases (modified Hodge test) was positive in 3 strains. In these 3 strains, MICs to selected antimicrobial agents (ertapenem, imipenem and meropenem) were determined by the E-test, as shown in Table 2.

All the three Acinetobacter baumannii strains originated from the Military Hospital. Strain no. 21678/C was isolated from blood culture of a patient with bloodstream infection staying at a department of anesthesiology and intensive care medicine. Samples nos. 12257/C and $15848 / \mathrm{C}$ were isolated from endotracheal secretions collected from two patients with late-onset ventilatorassociated pneumonia hospitalized at a department of chronic intensive care.

Genetic determination of the presence of resistance genes confirmed the presence of a gene encoding class D carbapenemase, namely OXA-23 enzyme in all three strains. Restriction fragment length polymorphism analysis in positive PCR amplicons and final confirmation by direct sequencing showed the presence of OXA-23 enzyme in all three Acinetobacter baumannii strains. Comparison of macrorestriction profiles of genomic DNA using PFGE revealed that the strains had an identical restriction profile. This suggested clonal spread of a genetically identical strain.

\section{Discussion}

Class D serine carbapenemase in an Acinetobacter baumannii strain was first reported in Scotland in 1985, that is, before imipenem started to be widely used in clinical practice (Paton et al., 1993; Carvalho et al., 2011). This enzyme, originally called ARI-I, was sequenced and subsequently labeled as OXA-23 (Scaife et al., 1995; Mugnier et al., 2010).

Until now, this enzyme has been reported in Acinetobacter baumannii strains throughout the world (Mugnier et al., 2010).

In the Czech republic a multiresistant strain of Acinetobacter baumannii carrying the genes for NDM-1 and OXA-23 was detected in 2011. However, this strain was isolated in a patient who had returned from a stay in Egypt and belonged to the European (EU) clone I (Kř́ižová et al., 2012). Thus, the above description of Acinetobacter baumannii strains producing OXA-23 is their first report in the Czech Republic in patients who did not stay abroad, suggesting their domestic origin. All three strains isolated from Military Hospital patients had a completely identical restriction profile, indicating

Table 2 MICs (in $\mathrm{mg} / \mathrm{L}$ ) of the tested carbapenems

\begin{tabular}{cccc}
\hline $\begin{array}{c}\text { Strain } \\
\text { no. }\end{array}$ & \multicolumn{3}{c}{ MIC $(\mathbf{m g} / \mathbf{L})$} \\
\cline { 2 - 4 } & Meropenem & Imipenem & Ertapenem \\
\hline $\mathbf{2 1 6 7 8 / C}$ & 12 & 16 & $>32$ \\
$\mathbf{1 2 2 5 7 / C}$ & $>32$ & 16 & $>32$ \\
15848/C & $>32$ & $>32$ & $>32$
\end{tabular}

E-test MICs testing. 
clonal spread of a strain carrying serine carbapenemase OXA-23 in this health care facility.

Increasing resistance of bacterial pathogens to antimicrobial agents poses a severe threat to management of many infections. Of particular risk is the rise in the use of carbapenems resulting from a high prevalence of ESBL- and AmpC-positive Enterobacteriaceae which may determine the development of resistance to this group of still effective drugs (Coelho et al., 2004). Our data suggest that in the case of Acinetobacter spp. strains, the prevalence of carbapenem-resistant isolates is low. However, this situation needs to be carefully monitored and if this type of resistance spreads it must be adequately analyzed using modern molecular biology methods.

\section{Consent}

Written informed consent was obtained from the patient for the publication of this report and any accompanying images.

\section{Competing interests}

The authors declare that they have no competing interest.

\section{Authors' contributions}

MS and MC had performed genetics testing, VH had carried out pulse field gel electrophoresis, PS had collected strains, JB had realized identification using MALDI and MK had determined susceptibility to antibiotics and phenotypic determination of carbapenemases. All authors read and approved the final version.

\section{Acknowledgments}

Supported by the grant project LF_2012_006.

Infrastructural part of this project (Institute of Molecular and Translational Medicine) was supported from the Operational Programme Research and Development for Innovations (project CZ.1.05/2.1.00/01.0030).

Many thanks to Ing. Jaroslav Hrabák, Ph.D. for providing bacterial strains with positive carbapenemase production.

\section{Author details \\ 'Department of Microbiology, Faculty of Medicine and Dentistry, Palacky University Olomouc, Hněvotínská 5, Olomouc 77900, Czech Republic. ${ }^{2}$ Institute of Molecular and Translational Medicine, Faculty of Medicine and Dentistry, Palacky University Olomouc, Hněvotínská 5, Olomouc 77900, Czech Republic. ${ }^{3}$ State Veterinary Institute in Olomouc, Jakoubka ze Střibra 1, Olomouc 77900, Czech Republic.}

Received: 12 April 2013 Accepted: 28 June 2013

Published: 2 July 2013

\section{References}

Acosta J, Merino M, Viedma E et al (2011) Multidrug-resistant Acinetobacter baumannii harboring OXA-24 carbapenemase, Spain. Emerg Infect Dis 17:1064-1067

Ambler RP (1980) The structure of $\beta$-lactamases. Philo Tran R Soc Lon B Biol Sci 289:321-331

Aubron C, Poirel L, Ash RJ et al (2005) Carbapenemase-producing Enterobacteriaceae, U.S. rivers. Emerg Infect Dis 11:260-264

Bogaerts P, Naas T, Wybo I et al (2006) Outbreak of infection by carbapenemresistant Acinetobacter baumannii producing the carbapenemase OXA-58 in Belgium. J Clin Microbiol 44:4189-4192

Bradford PA, Bratu S, Urban C et al (2004) Emergence of carbapenem-resistant Klebsiella species possessing the class A carbapenemhydrolyzing KPC-2 and inhibitor-resistant TEM-30 beta-lactamases in New York City. Clin Infect Dis $39: 55-60$
Bush K, Jacoby GA (2010) Updated functional classification of $\beta$-lactamases. Antimicrob Agent Chemother 54:969-976

Carvalho KR, D'Alincourt Carvalho-Assef AP, Galvão dos Santos L et al (2011) Occurrence of blaoXA-23 gene in imipenem-susceptible Acinetobacter baumannii. Mem Inst Oswaldo Cruz 106:505-506

Coelho J, Woodford N, Livermore DM (2004) Multiresistant acinetobacter in the UK: how big a threat? J Hosp Infect 58:167-169

Coelho JM, Turton JF, Kaufmann ME et al (2006) Occurrence of carbapenemresistant Acinetobacter baumannii clones at multiple hospitals in London and Southeast England. J Clin Microbiol 44:3623-3627

Corvec S, Poirel L, Naas T et al (2007) Genetics and expression of the carbapenem-hydrolyzing oxacillinase gene bla OXA-23 in Acinetobacter baumannii. Antimicrob Agents Chemother 51:1530-1533

Dalla-Costa LM, Coelho JM, Souza HAPHM et al (2003) Outbreak of carbapenemresistant Acinetobacter baumannii producing the OXA-23 enzyme in Curitiba, Brazil. J Clin Microbiol 41:3403-3406

Dijkshoorn L, Nemec A, Seifert H (2007) An increasing threat in hospitals: multidrug-resistant Acinetobacter baumannii. Natur Rev Microbiol 5:939-951

Donald HM, Scaife W, Amyes SG et al (2000) Sequence analysis of ARI-1, a novel OXA beta-lactamase, responsible for imipenem resistance in Acinetobacter baumannii 6B92. Antimicrob Agents Chemother 44:196-199

European Committee on Antimicrobial Susceptibility Testing (2012) Växjö. Breakpoint tables for interpretation of MICs and zone diameters, Sweden, Available from: http://www.eucast.org/clinical_breakpoints

Higgins PG, Poirel L, Lehmann M et al (2009) OXA-143, a novel carbapenemhydrolyzing class $D$-lactamase in Acinetobacter baumannii. Antimicrob Agents Chemother 53:5035-5038

Higgins PG, Dammhayn C, Hackel M et al (2010) Global spread of carbapenemresistant Acinetobacter baumannii. J Antimicrob Chemother 65:233-238

Hsueh P-R, Teng L-J, Chen C-Y et al (2002) Pandrug-resistant Acinetobacter baumannii causing nosocomial infections in a university hospital, Taiwan. Emerg Infect Dis 8:827-832

Husičková V, Čekanová L, Chromá M et al (2012) Carriage of ESBL- and AmpCpositive Enterobacteriaceae in the gastrointestinal tract of community subjects and hospitalized patients in the Czech Republic. Biomed Pap Med Fac Univ Palacky Olomouc Czech Repub 156:348-353

Jeon BC, Jeong SH, Bae IK et al (2005) Investigation of a nosocomial outbreak of imipenem-resistant Acinetobacter baumannii producing the OXA-23 betalactamase in Korea. J Clin Microbiol 43:2241-2245

Kim JW, Heo ST, Jin JS et al (2008) Characterization of Acinetobacter baumannii carrying bla OXA-23, $_{\text {b }} a_{\text {PER-1 }}$ and armA in a Korean hospital. Clin Microbiol Infect 14:716-718

Krrižová L, Bonnin RA, Nordmann P et al (2012) Characterization of a multidrugresistant Acinetobacter baumannii strain carrying the bla $\mathrm{ADM}_{\mathrm{ND}-1}$ and bla $\mathrm{aXA}_{\mathrm{A}-23}$ from the Czech republic. J Antimicrob Chemother 67:1550-1552

Lee K, Chong Y, Shin HB et al (2009) Modified Hodge and EDTA-disk synergy tests to screen metallo- $\beta$-lactamase-producing strains of Pseudomonas and Acinetobacter species. J Clin Microbiol 47:1631-1639

Lolans K, Rice TW, Munoz-Price LS, Quinn JP (2006) Multicity outbreak of carbapenem-resistant Acinetobacter baumannii isolates producing the carbapenemase OXA-40. Antimicrob Agents Chemother 50:2941-2945

Luna CM, Vujacich P, Niederman MS et al (1997) Impact of BAL data on the therapy and outcome of ventilator-associated pneumonia. Chest 111:676685

Marais E, de Jong G, Ferraz $V$ et al (2004) Interhospital transfer of pan-resistant Acinetobacter strains in Johannesburg, South Africa. Am J Infect Control 32:278-281

Mendes RE, Bell JM, Turnidge JD et al (2009) Emergence and widespread dissemination of OXA-23, $-24 / 40$ and -58 carbapenemases among Acinetobacter spp. in Asia-Pacific nations: report from the SENTRY surveillance program. J Antimicrob Chemother 63:55-59

Merkier AK, Catalano M, Ramirez MS et al (2008) Polyclonal spread of blaOXA-23 and blaOXA-58 in Acinetobacter baumannii isolates from Argentina. J Infect Dev Countr 2:235-240

Micek ST, Lloyd AE, Ritchie DJ et al (2005) Pseudomonas aeruginosa bloodstream infection: importance of appropriate initial antimicrobial treatment. Antimicrob Agents Chemother 49:1306-1311

Mugnier PD, Poirel L, Naas T et al (2010) Worldwide Dissemination of the bla $a_{0 \times A-23}$ Carbapenemase Gene of Acinetobacter baumannii. Emerg Infect Dis 16:35-40

Nemec A, Kŕrižová L, Maixnerová M et al (2008) Emergence of carbapenem resistance in Acinetobacter baumannii in the Czech republic is associated 
with the spread of multidrug-resistant strains of European clone II. J Antimicrob Chemother 62:484-489

Pasteran F, Mendez T, Guerriero L et al (2009) Sensitive screening tests for suspected class A carbapenemase production in species of Enterobacteriaceae. J Clin Microbiol 47:1631-1639

Paton R, Miles RS, Hood J et al (1993) ARI-1: beta-lactamase-mediated imipenem resistance in Acinetobacter baumannii. Int J Antimicrob Agents 2:81-88

Peleg AY, Bell JM, Hofmeyr A et al (2006) Inter-country transfer of Gram-negative organisms carrying the VIM-4 and OXA-58 carbapenem-hydrolysing enzymes. J Antimicrob Chemother 57:794-795

Peleg AY, Seifert H, Paterson DL (2008) Acinetobacter baumannii: emergence of a successful pathogen. Clin Microbiol 21:538-582

Poirel L, Heritier C, Toluen V et al (2004) Emergence of oxacillinase-mediated resistance to imipenem in Klebsiella pneumoniae. Antimicrob Agents Chemother 48:15-22

Poirel L, Naas T, Nordmann P (2010) Diversity, epidemiology, and genetics of class D beta-lactamases. Antimicrob Agents Chemother 54:24-38

Pournaras S, Poulou A, Tsakris A (2010) Inhibitor-based methods for the detection of KPC carbapenemase-producing Enterobacteriaceae in clinical practice by using boronic acid compounds. J Antimicrob Chemother 65:1319-1321

Queenan AM, Torres-Viera C, Gold HS et al (2000) SME-type carbapenemhydrolyzing class A $\beta$-lactamases from geographically diverse Serratia marcescens strains. Antimicrob Agents Chemother 44:3035-3039

Radice M, Power P, Gutkind G et al (2004) First class A carbapenemase isolated from Enterobacteriaceae in Argentina. Antimicrob Agents Chemother 48:1068-1069

Rello J, Torres A, Ricart M et al (1994) Ventilator-associated pneumonia by Staphylococcus aureus. Comparison of methicillin-resistant and methicillinsensitive episodes. Am J Respir Crit Care Med 150:1545-1549

Scaife W, Young HK, Paton RH et al (1995) Transferable imipenem-resistance in Acinetobacter species from a clinical source. J Antimicrob Chemother 36:585-586

Stoeva T, Higgins PG, Bojkova K et al (2008) Clonal spread of carbapenemresistant OXA-23-positive Acinetobacter baumannii in a Bulgarian university hospital. Clin Microbiol Infect 14:723-727

Trecarichi EM, Tubarello M, Caira M et al (2011) Multidrug resistant Pseudomonas aeruginosa bloodstream infection in adult patients with hematologic malignancies. Haematologica 96:e1-e3

Tsakris A, Ikonomidis A, Poulou A (2008) Clusters of imipenem-resistant Acinetobacter baumannii clones producing different carbapenemases in an intensive care unit. Clin Microbiol Infect 14:588-594

Uvizl R, Hanulik V, Husickova V et al (2011) Hospital-acquired pneumonia in ICU patients. Pap Med Fac Univ Palacky Olomouc Czech Repub 155:373-378

Van Den Broek PJ, Arends J, Bernards AT et al (2006) Epidemiology of multiple Acinetobacter outbreaks in The Netherlands during the period 1999-2001. Clin Microbiol Infect 12:837-843

Villegas MV, Kattan JN, Correa A et al (2007) Dissemination of Acinetobacter baumannii clones with OXA-23 carbapenemase in Colombian hospitals. Antimicrob Agents Chemother 51:2001-2004

Weldhagen GF, Prinsloo A (2004) Molecular detection of GES-2 extended spectrum beta-lactamase producing Pseudomonas aeruginosa in Pretoria, South Africa. Int J Antimicrob Agents 24:35-38

Wybo I, Blommaert L, De Beer T et al (2007) Outbreak of multidrug-resistant Acinetobacter baumannii in a Belgian university hospital after transfer of patients from Greece. J Hosp Infect 67:374-380

Zarrilli M, Giannouli M, Tomasone F et al (2009) Carbapenem resistance in Acinetobacter baumannii: the molecular epidemic features of an emerging problem in health care facilities. J Infect Dev Ctries 3:335-340

Zong Z, Lü X, Valenzuela JK et al (2008) An outbreak of carbapenem-resistant Acinetobacter baumannii producing OXA-23 carbapenemase in western China. Int J Antimicrob Agents 31:50-54

doi:10.1186/2193-1801-2-296

Cite this article as: Senkyrikova et al: Acinetobacter baumannii producing OXA-23 detected in the Czech Republic. SpringerPlus 2013 2:296.

\section{Submit your manuscript to a SpringerOpen ${ }^{\circ}$ journal and benefit from:}

- Convenient online submission

- Rigorous peer review

- Immediate publication on acceptance

- Open access: articles freely available online

- High visibility within the field

- Retaining the copyright to your article

Submit your next manuscript at $\gg$ springeropen.com 